Acknowledgements: Professional medical writing and editorial assistance was provided by Fiona Boswell, PhD, at Caudex and was funded by Bristol Myers Squibb. This study was funded by Bristol Myers Squibb.

Disclosure of Interests: Rieke Alten Speakers bureau: AbbVie, Bristol Myers Squibb, Gilead, Janssen, Lilly, Pfizer, Consultant of: AbbVie, Bristol Myers Squibb, Gilead, Janssen, Lilly, Pfizer, Grant/research support from: AbbVie, Bristol Myers Squibb, Gilead, Janssen, Lilly, Pfizer, Xavier Mariette Consultant of: Bristol Myers Squibb, Galapagos, Gilead, GlaxoSmithKline, Janssen, Pfizer, UCB, Rene-Marc Flipo Speakers bureau: AbbVie, Bristol Myers Squibb, Janssen, Lilly, Medac, Merck Sharp \& Dohme, Novartis, Pfizer, Roche-Chugai, Grant/ research support from: Amgen, Janssen, Novartis, Pfizer, Roberto Caporali Speakers bureau: AbbVie, Amgen, Bristol Myers Squibb, Celltrion, Fresenius Kabi, Galapagos, Gilead, Lilly, Merck Sharp \& Dohme, Pfizer, Roche, Samsung Bioepis, Sanofi, UCB, Consultant of: Galapagos, Gilead, Janssen, Lilly, Merck Sharp \& Dohme, Maya H Buch Speakers bureau: AbbVie, Consultant of: AbbVie, Eli Lilly, Gilead, Merck Serono, Pfizer, Roche, Sanofi, Grant/research support from: Gilead, Pfizer, Roche, UCB, Yusuf Patel: None declared, Sara Marsal Speakers bureau: Bristol Myers Squibb, Celgene, Pfizer, Roche, Sanofi, UCB, Consultant of: AbbVie, Bristol Myers Squibb, Celgene, Galapagos, Merck Sharp \& Dohme, Pfizer, Roche, Sanofi, UCB, Grant/research support from: AbbVie, Bristol Myers Squibb, Celgene, Janssen, Merck Sharp \& Dohme, Novartis, Pfizer, Roche, Sanofi, UCB, M.T. Nurmohamed Speakers bureau: AbbVie, Bristol Myers Squibb, Eli Lilly, Roche, Sanofi, Consultant of: AbbVie, Celgene, Celltrion, Eli Lilly, Janssen, Grant/research support from: AbbVie, Bristol Myers Squibb, Celgene, Eli Lilly, Janssen, Merck Sharp \& Dohme, Mundipharma, Novartis, Pfizer, Roche, Sanofi, Hedley Griffiths Consultant of: AbbVie, Gilead, Janssen, Novartis, Peter Peichl: None declared, Bettina Bannert: None declared, Adrian Forster: None declared, Melanie Chartier Shareholder of: Bristol Myers Squibb, Employee of: Bristol Myers Squibb, Yedid Elbez Consultant of: Bristol Myers Squibb, Christiane Rauch Shareholder of: Bristol Myers Squibb, Employee of: Bristol Myers Squibb, Karissa Lozenski Shareholder of: Bristol Myers Squibb, Employee of: Bristol Myers Squibb, Vadim Khaychuk Shareholder of: Bristol Myers Squibb, Employee of: Bristol Myers Squibb DOI: 10.1136/annrheumdis-2021-eular.903

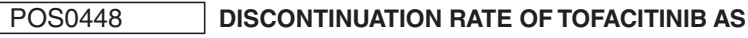 MONOTHERAPY IS SIMILAR COMPARED TO COMBINATION THERAPY WITH METHOTREXATE IN RHEUMATOID ARTHRITIS PATIENTS: POOLED DATA FROM TWO RHEUMATOID ARTHRITIS REGISTRIES IN CANADA}

M. Movahedi ${ }^{1}$, D. Choquette ${ }^{2}$, L. Coupal ${ }^{2}$, A. Cesta ${ }^{1}$, X. Li ${ }^{1}$, E. Keystone ${ }^{3}$, C. Bombardier ${ }^{1}$ on behalf of OBRI and RHUMADATA Investigators. ${ }^{1} \mathrm{UHN}$, Toronto General Hospital Research Institute, Toronto, Canada; ${ }^{2}$ Institut de Rhumatologie de Montréal, RHUMADATA, Montreal, Canada; ${ }^{3}$ University of Toronto, Medicine, Toronto, Canada

Background: Tofacitinib (TOFA) is an oral, small molecule drug used for rheumatoid arthritis (RA) treatment and is prescribed alone or with methotrexate (MTX). We previously reported the similarity in retention between TOFA monotherapy and TOFA with MTX using data from two different registries separately; the Ontario Best Practices Research Initiative (OBRI) and the Quebec registry RHUMADATA.

Objectives: To increase the study power, we propose to evaluate the discontinuation rate (due to any reason) of TOFA with and without MTX, using pooled data from these two registries.

Methods: RA patients enrolled in the OBRI and RHUMADATA initiating their TOFA between $1^{\text {st }}$ June 2014 (TOFA approval date in Canada) and $31^{\text {st }}$ Dec 2019 were included. Concurrent MTX use was defined as MTX use for more than $75 \%$ of the time while using TOFA. Multiple imputation (Imputation Chained Equation method, $\mathrm{N}=20$ ) was used to deal with missing data for covariates at treatment initiation.

Time to discontinuation was assessed using Cox regression models. To deal with confounding by indication, we estimated propensity scores for selected covariates with an absolute standard difference greater than 0.1 . We then adjusted Cox regression models for propensity quantile to compare the discontinuation of TOFA with MTX versus TOFA without MTX.

Results: A total of 493 patients were included. Of those, 244 (49.5\%) and 249 $(51.5 \%)$ were treated with MTX and without MTX, respectively. Compared to TOFA monotherapy, the TOFA with MTX group had a significantly lower mean HAQ-DI, fatigue score, and the number of prior biologic use at the time of TOFA initiation. A lower proportion of positive ACPA (59\% vs. $66 \%$ ), prevalence of hypertension ( $31 \%$ vs $37 \%$ ), and concomitant use of Leflunomide ( $11 \%$ vs. $23 \%$ ) were also observed for patients using TOFA with MTX.

Over a mean follow-up of 19.0 months, discontinuation was reported in 182 $(36.9 \%)$ of all TOFA patients. After adjusting for propensity score quantile across
20 imputed datasets, there was no significant difference in discontinuation between treatment groups (adjusted HRs: $1.12,95 \% \mathrm{Cl}: 0.83-1.51 ; \mathrm{p}=0.49$ ).

Conclusion: In this pooled real-world data study, we found that in patients with RA, the retention of TOFA is similar if it is used as monotherapy or in combination with MTX.

Disclosure of Interests: Movahedi: None declared, Denis Choquette Grant/ research support from: Rhumadata is supported by unrestricted grants from Abbvie Canada, Amgen Canada, Eli Lilly Canada, Novartis Canada, Pfizer Canada Sandoz Canada and Sanofi Canada., Louis Coupal: None declared, Angela Cesta: None declared, Xiuying Li: None declared, Edward Keystone Grant/research support from: Amgen, Merck, Pfizer Pharmaceuticals, PuraPharm. Speaker Honoraria Agreements: AbbVie, Amgen, Bristol-Myers Squibb Company, Celltrion, Myriad Autoimmune, F. Hoffmann-La Roche Inc, Gilead, Janssen Inc, Lilly Pharmaceuticals, Merck, Pfizer Pharmaceuticals, Sandoz, Sanofi-Genzyme, Samsung Bioepsis Consulting Agreements/Advisory Board Membership: AbbVie, Amgen, Bristol-Myers Squibb Company, Celltrion, Myriad Autoimmune, F. Hoffmann-La Roche Inc Gilead, Janssen Inc, Lilly Pharmaceuticals, Merck, Pfizer Pharmaceuticals, Sandoz, Sanofi-Genzyme, Samsung Bioepsis, Claire Bombardier Grant/research support from: OBRI was funded by peer reviewed grants from $\mathrm{CIHR}$ (Canadian Institute for Health Research), Ontario Ministry of Health and Long-Term Care (MOHLTC), Canadian Arthritis Network (CAN) and unrestricted grants from: Abbvie, Amgen, Aurora, Bristol-Meyers Squibb, Celgene, Hospira, Janssen, Lilly, Medexus, Merck, Novartis, Pfizer, Roche, Sanofi, \& UCB.

Acknowledgment: : Dr. Bombardier held a Canada Research Chair in Knowledge Transfer for Musculoskeletal Care and a Pfizer Research Chair in Rheumatology

DOI: 10.1136/annrheumdis-2021-eular.920

\section{POS0449 \\ BIOLOGICS INITIATION IN MODERATE VS SEVERE RHEUMATOID ARTHRITIS PATIENTS: PROSPECTIVE OBSERVATIONAL STUDY FROM A CANADIAN REGISTRY}

N. Guo ${ }^{1}$, X. $\mathrm{Li}^{2}, \mathrm{M} . \mathrm{Movahedi}^{2}, \mathrm{~A}$. Cesta $^{2}, \mathrm{C}$. Bombardier ${ }^{2}$ on behalf of OBRI Investigators. ${ }^{1}$ Kingstone Health Sciences Centre, Health Science, Kingstone, Canada; ${ }^{2}$ UHN, Toronto General Hospital Research Institute, Toronto, Canada

Background: Prior studies have shown that in the real-world setting, rheumatoid arthritis (RA) patients have lower disease activity than those studied in clinical trials. However, randomized controlled trials for biologics continue to mainly recruit patients with severe disease.

Objectives: To assess the implications of this practice, our study investigates the proportion of patients achieving remission (DAS28-ESR $\leq 2.6$ ), in RA patients with moderate disease activity and severe disease activity, at 12 months post starting their first biologic, and identifies baseline predictors of biologic response. Methods: This study included RA patients who have never been treated with a biologic and initiated their first biologic while enrolled in the Ontario Best Practices Research Initiative (OBRI) registry, between 2008 and 2019. Patients selected had either moderate RA (DAS28 $\geq 3.2$ to $\leq 5.1$ ) or severe RA (DAS28 $>5.1$ ). Comparisons were made between the moderate and severe disease groups using the student's t-test for continuous variables, and the chi-square tes for categorical variables. Multivariable logistic regression was used to test potential predictors of remission. Backward stepwise model selection was applied to select variables with $p$-value $\leq 0.10$. Multiple imputation (MCMC method; $n=20$ ) was used to impute missing data.

Results: Overall, 641 patients initiated their first biologic, 483 had follow up data at 12 months (moderate disease activity=264; severe disease activity=219). In the moderate group, the mean age (SD) was 55.7 (13.1) and $80 \%$ were female. In the severe group, mean age (SD) was 58.4 (12.3) and $81 \%$ were female. At time of biologic initiation, the mean DAS28 for the moderate group was $4.1(0.5)$, and 6.0 (0.6) for the severe group. After 12 months of starting a biologic, the proportion of patients achieving remission was $50 \%$ in the moderate group, and $23 \%$ in the severe group $(p<0.0001)$. In contrast, the proportion of patients achieving significant clinical change from baseline (improvement in DAS28 $\geq 1.2$ ) was $78 \%$ in the severe group, compared to $66 \%$ in the moderate group $(p=0.0049)$. More specifically, the absolute improvement in DAS28 after 12 months was higher in the severe group at 2.2 (1.5), compared to a change of $1.4(1.3)$ in the moderate group $(p<0.0001)$. Negative predictors of remission include female gender (odds ratio (OR), $0.57,95 \%$ confidence interval (CI), 0.33-0.97; $p=0.039$ ), and higher HAQ-DI score (OR 0.49, 95\% Cl 0.36$0.68 ; p<0.001)$. In turn, moderate disease at time of biologic initiation (OR 2.38, 95\% CI 1.50-3.79; $p=0.0390$ ) was identified as a positive predictor of remission.

Conclusion: This prospective cohort study found RA patients with moderate disease activity are more likely to reach targeted states (remission and low disease activity), whereas severe patients have greater absolute improvements in DAS28 and HAQ-DI but are less likely to achieve remission. Moderate disease is a positive predictor for remission, whereas female gender and a higher HAQ-DI score are negative predictors 